Bull. Mater. Sci., Vol. 39, No. 7, December 2016, pp. 1819-1825. (C) Indian Academy of Sciences.

\title{
Linear and non-linear optical properties of amorphous $\mathrm{Se}$ and $\mathrm{M}_{5} \mathrm{Se}_{95}$ $(\mathrm{M}=\mathrm{Ge}$, Ga and $\mathrm{Zn})$ films
}

\author{
GH. ABBADY ${ }^{1}$, K A ALY ${ }^{2,3, *} \mathbb{D}$, Y SADDEEK ${ }^{2}$ and N AFIFIY ${ }^{1}$ \\ ${ }^{1}$ Department of Physics, Faculty of Science, Assuit University, Assuit 71516, Egypt \\ ${ }^{2}$ Physics Department, Faculty of Science and Arts Khulais, University of Jeddah, Jeddah 21589, Saudi Arabia \\ ${ }^{3}$ Physics Department, Faculty of Science, Al-Azhar University, Assiut Branch, Assiut 71524, Egypt
}

MS received 8 December 2015; accepted 2 May 2016

\begin{abstract}
The variations in structure and optical properties of amorphous a-Se and a- $\mathrm{M}_{5} \mathrm{Se}_{95}(\mathrm{M}=\mathrm{Ge}, \mathrm{Ga}$ and Zn) films have been studied based on FTIR and optical measurements. FTIR transmittance spectra for a-Se and $\mathrm{a}_{-} \mathrm{M}_{5} \mathrm{Se}_{95}(\mathrm{M}=\mathrm{Ge}, \mathrm{Ga}$ and $\mathrm{Zn}$ ) glasses were measured as a function of wavenumber. The addition of $\mathrm{Ge}, \mathrm{Ga}$ and $\mathrm{Zn}$ increases the vibrational frequency of the a-Se main band. The absorption edge of $\mathrm{Ge}_{5} \mathrm{Se}_{95}$ shifted towards long side of the wavelength in comparison with that of a-Se film. This shift increases gradually in the case of Ga5Se95 and $\mathrm{Zn}_{5} \mathrm{Se}_{95}$ films. So, the optical bandgap of $\mathrm{M}_{5} \mathrm{Se}_{95}$ films was decreased, but the index of refraction was increased. The first and third order of electric susceptibility $\left(\chi^{(1)}\right.$ and $\left.\chi^{(3)}\right)$ and non-linear index of refraction $\left(n_{2}\right)$ were increased by adding Ge, Ga and Zn into a-Se.
\end{abstract}

Keywords. Thin films; vapour deposition; infrared spectroscopy; optical properties.

\section{Introduction}

Optical switching devices play an important role in the field of signal transmission that requires high speeds and bit rates [1]. Optical fibres based on silicate glasses were preferred for fibre communication [2,3] because of their low loss and high interaction length. Although the low non-linear refractive index of silica requires a high switching power and too long length of fibre [3], silicate glasses have several orders of non-linearity low in comparison with chalcogenide glasses; therefore, chalcogenides have ultra-fast response time [4]. Selenium-based glasses have good thermo-mechanical properties. It could be easily shaped into optical devices, such as lenses and optical fibres. Selenide glass fibres have been proved to be suitable for infrared sensing in an original spectroscopic method, named fibre evanescent wave spectroscopy (FEWS). FEWS has provided good and promising results, for example, for medical diagnosis [5].

Among Se-based glasses, the amorphous Ga-Se system has been reported to be used in optical memory applications, but in crystalline state it can be used in IR detector, solar cells, a compound semiconductor heterostructure [68]. Strong covalent bonding in the $\mathrm{Se}-\mathrm{Ga}-\mathrm{Ga}-\mathrm{Se}$ layers and weak Vander Waals interlayer bonding with a small ioniccovalent contribution bring about lamination in GaSe and pronounced anisotropy of its properties, i.e., optical characteristics, electrical conductivity and so on. Significant birefringence makes it promising to use GaSe in the fabrication

\footnotetext{
*Author for correspondence (kamalaly2001@gmail.com)
}

of polarization-sensitive photodetectors, emitters, nuclear detectors and as sources of terahertz laser radiation [9].

The Ge-Se glasses are interesting materials in IR optics because of their large range of transparency from 0.6 to $\sim 30 \mu \mathrm{m}$. Moreover, the Ge-Se system has good mechanical and chemical properties, such as hardness, low internal stress adhesion and water resistance [10]. Optical properties of the Ge-Se system have been reported by many authors [11-15]. Binary $\mathrm{Zn}-\mathrm{Se}$ glasses is technically important as semiconductor luminescence materials; it was a candidate for blue light-emitting diodes and laser diodes [16]. In recent years, considerable efforts have been made to prepare $\mathrm{ZnSe}$ nanocrystals by wet-chemical method [17]. Moreover, $\mathrm{ZnSe}$ is used as buffer layer materials in Cu-based solar cells [18]. So, Ga, Ge and $\mathrm{Zn}$ have been chosen as a dopant to study their influence on the structure and optical properties of a-Se. Therefore, in the present study an effort has been made to investigate the effect of $\mathrm{Ga}, \mathrm{Ge}$ and $\mathrm{Zn}$ with low proportions (5 at.\%) on the structure, linear and non-linear optical properties of a-Se in the chemical form of $\mathrm{M}_{5} \mathrm{Se}_{95}(\mathrm{M}=\mathrm{Ga}$, $\mathrm{Ge}$ and $\mathrm{Zn}$ ) thin films.

\section{Experimental}

Bulk glasses of $\mathrm{Se}$ and $\mathrm{M}_{5} \mathrm{Se}_{95}(\mathrm{M}=\mathrm{Ge}, \mathrm{Ga}$ and $\mathrm{Zn}$ ) were prepared starting with high purity (99.999\%) of Se, $\mathrm{Ga}$, Ge and $\mathrm{Zn}$ by the usual melt quench technique. The non-crystalline structure of the prepared films was checked using a Philips X-ray diffractometer (PW1710). Some of the formed glasses of Se and $\mathrm{M}_{5} \mathrm{Se}_{95}(\mathrm{M}=\mathrm{Ga}$, Ge and $\mathrm{Zn}$ ) were crushed into powder and their IR spectra were 
measured using IR Fourier transformation spectrophotometer type (JASCO, FT/IR-430 (Japan)). Details of IR measurements were mentioned in a previous work [19]. The glass density $(\rho)$ for $\mathrm{Se}$ and $\mathrm{M}_{5} \mathrm{Se}_{95}$ glasses was measured by Archimedes method using the hydrostatic weighting in toluene as detailed here [20]. Based on the $\rho$-values the molar volume $V_{\mathrm{m}}$ was calculated according to their relation $\left(V_{\mathrm{m}}=M / \rho\right)$, where $M$ is the molecular weight of the glass. Amorphous films were deposited onto cleaned glass substrates by thermal evaporation of bulk ingots of these alloys $[21,22]$. The chemical compositions of the deposited films were measured using energy dispersive X-ray spectroscopy (Link analytical EDS). The determined compositions were so agreed with those of the starting materials to within \pm 1 at.\%.

A double-beam computer-controlled spectrophotometer (Jasco V-670 combined with PC) was used to measure both the optical transmittance and reflectance at normal incidence in the 400-2500 $\mathrm{nm}$ spectral range. The spectrophotometer was set with a slit-width of $1 \mathrm{~nm}$ and as this was much smaller than the line widths it was unnecessary to make a slit-width correction. Without a glass substrate in the reference beam, the measured transmittance spectra were used to investigate both film thickness and the optical constants with high accuracy through the envelope method that is detailed here [23].

\section{Results and discussions}

Some of the physical properties of the constituent elements of the binary glasses $\mathrm{A}_{x} \mathrm{~B}_{100-x}$ are listed in table 1 . The mean coordination number $(r)$ of binary glasses is the bonding character in the nearest neighbouring region and it can be expressed as [24]

$$
r=\left(x r_{\mathrm{A}}+(100-x) r_{\mathrm{B}}\right) / 100,
$$

Table 1. Some physical properties of various elements.

\begin{tabular}{lccccc}
\hline Element & $\begin{array}{c}\rho, \\
\mathrm{g} \mathrm{m}^{-3}\end{array}$ & $\begin{array}{c}\text { Molecular } \\
\text { weight }\end{array}$ & $\begin{array}{c}\chi \\
{[27]}\end{array}$ & $r$ & $\begin{array}{c}D, \mathrm{kcal} \mathrm{mol}^{-1} \\
{[23,25,26]}\end{array}$ \\
\hline $\mathrm{Se}$ & 4.819 & 78.96 & 2.55 & 2 & 44.04 \\
$\mathrm{Ge}$ & 5.323 & 72.63 & 2.01 & 4 & 37.78 \\
$\mathrm{Ga}$ & 5.904 & 69.72 & 1.81 & 5 & 34.19 \\
$\mathrm{Zn}$ & 7.140 & 65.38 & 1.65 & 6 & 48.69 \\
\hline
\end{tabular}

where $r_{\mathrm{A}}$ and $r_{\mathrm{B}}$ are the coordination numbers of the atoms $\mathrm{A}$ and $\mathrm{B}$, respectively, of the binary $\mathrm{A}_{x} \mathrm{~B}_{100-x}$ glasses.

From an energy point of view, in the case of $\mathrm{Ge}_{5} \mathrm{Se}_{95}$ glass, the heteropolar $\mathrm{Ge}-\mathrm{Se}$ bonds are preferred over $\mathrm{Se}-\mathrm{Se}$ homopolar bonds, but in $\mathrm{Ga}_{5} \mathrm{Se}_{95}$ and $\mathrm{Zn}_{5} \mathrm{Se}_{95}$ glasses the $\mathrm{Ga}-\mathrm{Se}$ and $\mathrm{Zn}-\mathrm{Se}$ bonds are preferred. This can be largely explained by CBA theory proposed by Biecerano and Ovshinsky [25]. According to this approach;

(1) The formation of heteropolar bonds was more favourable than the formation of homopolar bond.

(2) Bonds are formed in the sequences of decreasing bond energy until all the available valances of the atoms are saturated. Each constituent is coordinated by $8-N$ atoms, where $N$ is the number of electrons in the outer shell and this is equivalent to neglecting the dangling bonds and the other valence defects.

(3) The existence of an excess of a certain type of atom leads to the formation of homopolar bonds; therefore, it is not possible to satisfy its valence requirements by bonding it to atoms of different kinds alone (see the example of Se$\mathrm{Se}$ bonds in table 2). After the formation of $\mathrm{Ge}-\mathrm{Se}, \mathrm{Ga}-\mathrm{Se}$ and $\mathrm{Zn}-\mathrm{Se}$ bonds in $\mathrm{M}_{5} \mathrm{Se}_{95}$ glasses, the remaining extra $\mathrm{Se}$ valances must be saturated by Se-Se homopolar bonds. Summing the bond energies of the bonds present in the glassy sample gives the cohesive energy, $\mathrm{CE}$, which measures the average bond strength of the glassy system. In the present glasses the cohesive energy has been found to increase with the addition of $\mathrm{Ge}, \mathrm{Ga}$ or $\mathrm{Zn}$ because of the formation of heteropolar bonds.

The mean coordination number, distribution of chemical bonds, cohesive energy (CE), glass density, molar volume and the IR peaks are listed in table 2. In this table the density of the glass was increased when Se atoms were replaced by $\mathrm{Ge}, \mathrm{Ga}$ and $\mathrm{Zn}$, but the molar volume was decreased. It is well known that, the glass density and molar volume are affected by the density and molar volume of the consistent elements, i.e., lighter and less dense $\mathrm{Se}$ atoms were replaced by denser and heavy Ge, Ga and $\mathrm{Zn}$ atoms (see tables 1 and 2). Figure 1 shows the XRD patterns for a-Se and $\mathrm{M}_{5} \mathrm{Se}_{95}(\mathrm{M}=$ $\mathrm{Ge}, \mathrm{Ga}$ and $\mathrm{Zn}$ ) films. The absence of any sharp lines or peaks confirmed the amorphous structure of the as-prepared film.

\subsection{Mid-infrared spectra}

A mid-infrared transmission spectrum provides valuable information about the atomic configuration of the glasses.

Table 2. Some physical properties of a-Se and $\mathrm{M}_{5} \mathrm{Se}_{95}(\mathrm{M}=\mathrm{Ge}, \mathrm{Ga}$ and $\mathrm{Zn})$ films.

\begin{tabular}{lccccccccr}
\hline \multicolumn{7}{c}{ Chemical bond distribution } & & & \\
Comp. & $R$ & Se-Se & Ge-Se & Ga-Se & Zn-Se & CE, eV & $\rho, \mathrm{g} \mathrm{cm}^{-3}$ & $V_{\mathrm{m}}, \mathrm{cm}^{3} \mathrm{~mol}^{-1}$ & $\mathrm{IR} \mathrm{peaks,}^{-1}$ \\
\hline$n^{\mathrm{a}-\mathrm{Se}}$ & 2.00 & 1 & - & - & - & 1.906 & 4.800 & 16.450 & 1095 \\
$\mathrm{Se}_{95} \mathrm{Ge}_{5}$ & 2.10 & 0.905 & 0.095 & - & - & 2.049 & 4.826 & 16.295 & $468,801,1075$ \\
$\mathrm{Se}_{95} \mathrm{Ga}_{5}$ & 2.15 & 0.884 & - & 0.116 & - & 2.171 & 4.855 & 16.168 & $468,803,1098$ \\
$\mathrm{Se}_{95} \mathrm{Zn}_{5}$ & 2.20 & 0.864 & - & - & 0.136 & 2.442 & 4.917 & 15.920 & $468,807,1099$ \\
\hline
\end{tabular}


The IR spectra of a-Se and $\mathrm{M}_{5} \mathrm{Se}_{95}$ alloys are presented in figure 2. The bond energies of various possible heteropolar bonds $\mathrm{Ge}-\mathrm{Se}, \mathrm{Ga}-\mathrm{Sb}$ and $\mathrm{Se}-\mathrm{Sb}$ have been calculated based on the bond energy and the electronegativity of $\mathrm{Se}, \mathrm{Ge}$, $\mathrm{Ga}$ and $\mathrm{Zn}$ atoms as well as previously detailed [26]. The bond energy values for $\mathrm{Se}-\mathrm{Se}$ and $\mathrm{Ge}-\mathrm{Ge}$ were taken from

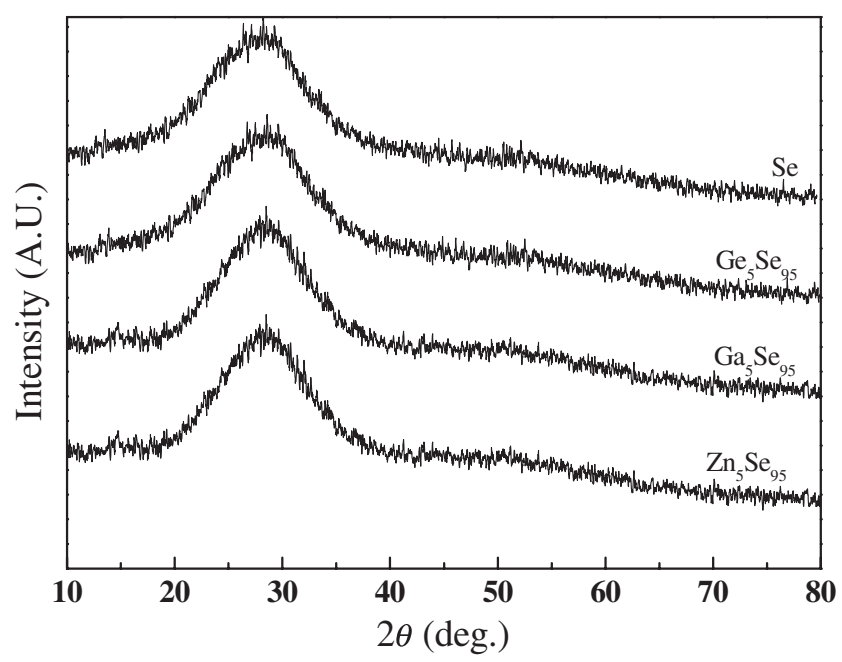

Figure 1. XRD patterns of the as-prepared $\mathrm{Se}$ and $\mathrm{M}_{5} \mathrm{Se}_{95}(\mathrm{M}=$ $\mathrm{Ge}, \mathrm{Ga}$ and $\mathrm{Zn}$ ) films. In the case of a-Se glass the main absorption bands appeared at $\sim 1095 \mathrm{~cm}^{-1}$.

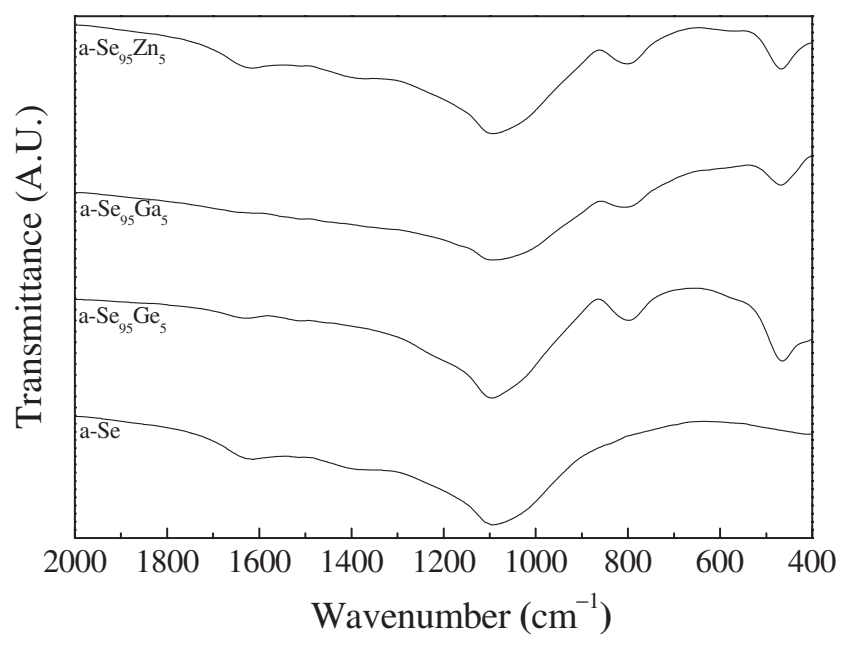

Figure 2. IR transmittance spectra of of a-Se and a- $\mathrm{M}_{5} \mathrm{Se}_{95}$ $(\mathrm{M}=\mathrm{Ge}, \mathrm{Ga}$ and $\mathrm{Zn})$ glasses. ref. [25], for $\mathrm{Zn}-\mathrm{Zn}$ bonds was taken from ref. [27] and for $\mathrm{Ga}-\mathrm{Ga}$ bonds was taken from ref. [24]. The electronegativity (Pauling) values for $\mathrm{Se}, \mathrm{Ge}, \mathrm{Ga}$ and $\mathrm{Zn}$ atoms were taken from webelements [28].

The existence of the absorption band is assigned to the vibrations of Se-Se bonds. Addition of $\mathrm{M}_{5}$ atoms ( $\mathrm{Ge}, \mathrm{Ga}$ and $\mathrm{Zn}$ ) into amorphous selenium results in two additional bands with lower energies located at $\sim 800$ and $466 \mathrm{~cm}^{-1}$. The band at $\sim 800 \mathrm{~cm}^{-1}$ may be attributed to the vibrations of M-Se-M ( $v_{1}$ mode), but the band at $\sim 465 \mathrm{~cm}^{-1}$ can be attributed to the vibrations of $\underline{S e_{8}}$ chains or may be attributed to the onset of saturation of Se bonds with $\mathrm{M}_{5}$ atoms. These results are in good agreement with Goyal and Maan [29].

The wavenumber of the vibration modes $(v)$ in the IR spectra can be calculated from the reduced mass of the molecule $\left(\mu=m_{1} m_{2} /\left(m_{1}+m_{2}\right)\right)$, taking into account their coordination. $m_{1}$ and $m_{2}$ are the masses of two atoms and the inter-atomic force within the groups of the atoms comprising the glass network $\left(K_{\mathrm{r}}\right)$ is given through the following relationship:

$$
v=\frac{K_{\mathrm{r}}}{\mu}
$$

where $K_{\mathrm{r}}$ is the force constant calculated according to Gordy [30] equation:

$$
K_{\mathrm{r}}=e N\left(\chi_{\mathrm{A}} \chi_{\mathrm{B}} / d^{2}\right)+b,
$$

where $e$ and $b$ are constants which depend on the structural unit type, $d$ is the bond length, $\chi_{\mathrm{A}}$ and $\chi_{\mathrm{B}}$ are the Pauling electronegativities and $N$ the bond order, which can be calculated based on the values of the covalent radii for single and double bonds ( $s_{1}$ and $s_{2}$ respectively) using the expression [31]:

$$
N=\frac{d+2 s_{1}-3 s_{2}}{2 d+s_{1}-3 s_{2}}
$$

Then the force constant $\left(K_{\mathrm{r}}\right)$ between two elements A and B can be determined by using [32]:

$$
K_{\mathrm{r}}=\left(K_{\mathrm{AA}} K_{\mathrm{BB}}\right)^{0.5}+\left(\chi_{\mathrm{A}}-\chi_{\mathrm{B}}\right),
$$

where $K_{\mathrm{AA}}$ and $K_{\mathrm{BB}}$ are the force constants for $\mathrm{A}-\mathrm{A}$ and B-B bonds, respectively. The experimental and theoretical values of wavenumber $(v)$, bond length, reduced mass and force constant are listed in table 3. From this table, one can see that the experimental values of the wavenumber and

Table 3. Experimental and theoretical values of wavenumber $(v)$, bond length, reduced mass and force constant for Se and $\mathrm{M}_{5} \mathrm{Se}_{95}$ films.

\begin{tabular}{lccccc}
\hline & & & \multicolumn{2}{c}{ Wavenumber $\left(\mathrm{cm}^{-1}\right)$} & \\
Glass & Bond length $(\mathrm{nm})$ & $\mu, \mathrm{kg} \mathrm{U}^{-1} \times 10^{-26}$ & Theoretical & Experimental & $K_{\mathrm{AB}}, N / m$ \\
\hline Se-Se & 0.115 & 6.55 & 500 & 468 & 581 \\
$\mathrm{Se}-\mathrm{Ge}$ & 0.1155 & 6.28 & 468 & - & 488 \\
$\mathrm{Se}-\mathrm{Ga}$ & 0.1158 & 6.15 & 455 & - & 452 \\
$\mathrm{Se}-\mathrm{Zn}$ & 0.1162 & 5.94 & 447 & - & 422 \\
\hline
\end{tabular}


consequently the stretching vibration modes differ from the theoretical computed values that can be attributed to the existence of more closely lying modes, which leads to the broadening in the absorption bands. Also, as the reduced mass decreased a clear shift in the vibrational frequency of the main band of vibration of a-Se towards higher frequencies is observed. It was mentioned before that heavier masses reduce the vibration of the host atoms [33].

\subsection{Optical properties}

The wavelength dependence of transmittance and reflectance spectra for a-Se [23] and $\mathrm{M}_{5} \mathrm{Se}_{95}(\mathrm{M}=\mathrm{Ge}, \mathrm{Ga}, \mathrm{Zn})$ films is shown in figure 3. A clear red shift of the absorption edge was observed with the addition of $\mathrm{Ge}, \mathrm{Ga}$ and $\mathrm{Zn}$ with 5 at.\% to the amorphous Se. The inset of figure 3 represents the absorption edge region of the a-Se and $\mathrm{M}_{5} \mathrm{Se}_{95}$ films. The two parts of the complex index of refraction real $(n)$ and imaginary $(k)$ have been evaluated using Swanepoel's envelope method [34]. The calculated values of the refractive index $(n)$ were plotted as a continues function of the wavelength (represented in figure 4a). It was observed that, the values of the refractive index decreases with increase in the wavelength showing a normal dispersion. With the addition of $\mathrm{Ga}, \mathrm{Ge}$ and $\mathrm{Zn}$, respectively, the refractive index increases as explained by LorentzLorenz relation. Here we replace Se atoms with smallest atomic radius, density and electropositive by the largest corresponding of $\mathrm{Ge}, \mathrm{Ga}$ or $\mathrm{Zn}$ atoms (table 1). Therefore, the increase in the refractive index can be attributed to the increase in the electronic polarizability. Figure $4 \mathrm{~b}$ represents the plots of extinction coefficient $(k) v s$. the incident photon energy $(h v)$ for a-Se and $\mathrm{M}_{5} \mathrm{Se}_{95}$ films. The $k$ values are correlated to the absorption coefficient as $(\alpha=$ $4 \pi k / \lambda)$. The value of $k$ increases with increase in photon

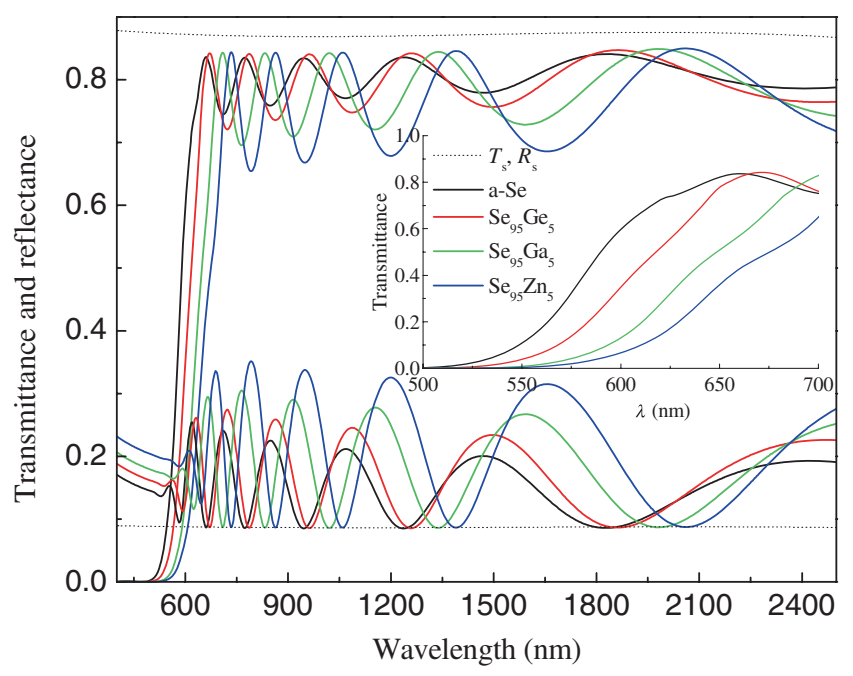

Figure 3. The transmittance and reflectance spectra of a-Se and $\mathrm{a}_{5} \mathrm{M}_{5} \mathrm{Se}_{95}(\mathrm{M}=\mathrm{Ge}, \mathrm{Ga}$ and $\mathrm{Zn})$ Films. The inset of figure investigates the region of strong absorption. energy, indicating that an increase in the fraction of light scattered in the interference-free region and it increases with the addition of $\mathrm{Ge}, \mathrm{Ga}$ or $\mathrm{Zn}$ to the amorphous Se. These results agree well with the results of FTIR.

In the region of strong absorption $\left(\alpha \geq 10^{4} \mathrm{~cm}^{-1}\right)$, the photon energy dependence of the absorption coefficient obeys Tauc's formula [35]:

$$
\alpha h v=B\left(h v-E_{\mathrm{g}}\right)^{P},
$$

where $E_{\mathrm{g}}$ is the optical bandgap, $B$ an energy independent constant that was correlated to the refractive index through the relation $\left(B=\left(e^{2} /\left(n c h^{2} m^{*}\right)\right)\left(2 m_{\mathrm{r}}\right)^{3 / 2}\right)$ and $P$ an integer or half-integer that determines the nature of optical transition ( $P=1 / 2$ for direct and $P=2$ for non-direct transitions). The linear relation of the absorption coefficient parameter $\sqrt{\alpha h v}$ $v s$. $h v$ for a-Se and MSe films is shown in figure $4 \mathrm{a}$, confirming that the transitions in the forbidden gap are indirect, i.e., $P=1 / 2$. The slope in figure 5 a shows that the $\sqrt{B}$ value was

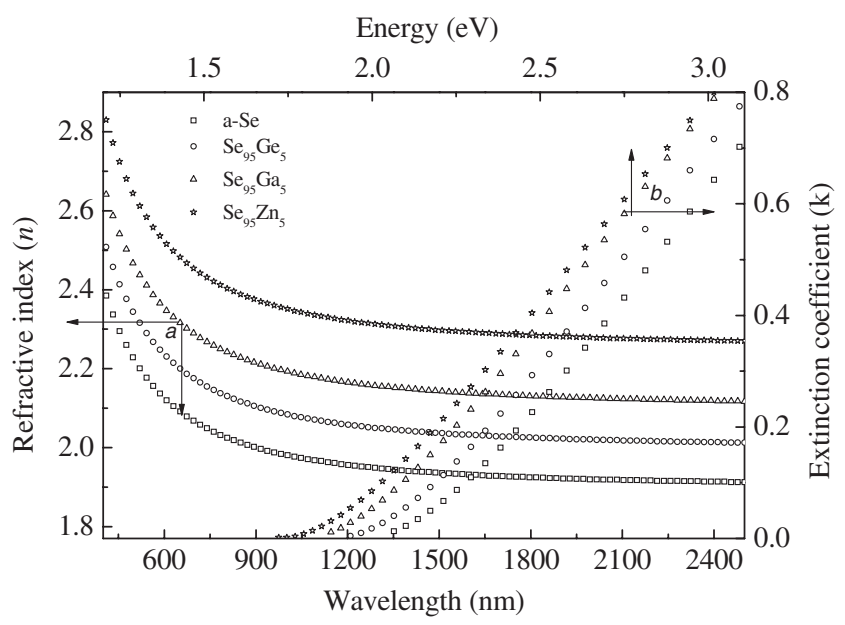

Figure 4. The real $(n)$ and imaginary $(k)$ parts of the complex index of refraction of a-Se and $\mathrm{a}_{-} \mathrm{Se}_{95} \mathrm{M}_{5}(\mathrm{M}=\mathrm{Ge}, \mathrm{Ga}$ and $\mathrm{Zn})$ films as a function of the wavelength and energy, respectively.

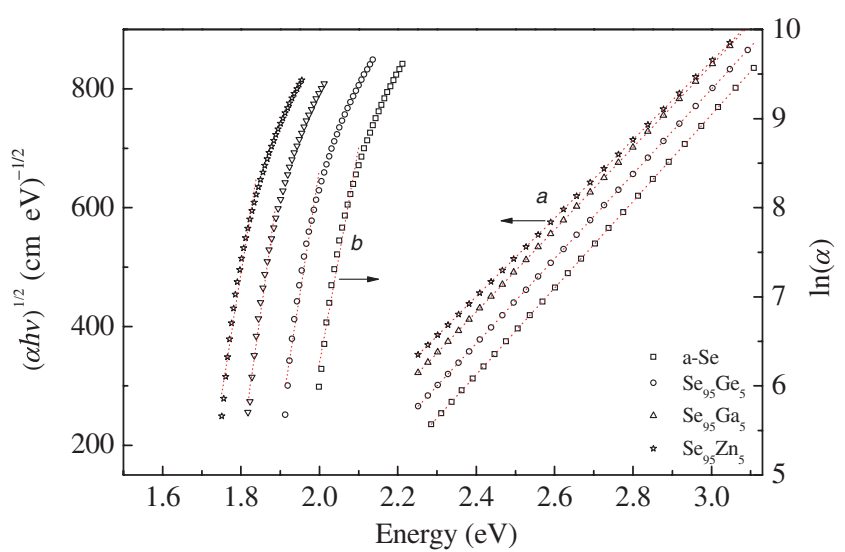

Figure 5. (a) The absorption coefficient in the form of $(\alpha h v)^{0.5}$ and (b) $\ln (\alpha)$ as a function of the incident photon energy for a-Se and $\mathrm{a}-\mathrm{Se}_{95} \mathrm{M}_{5}(\mathrm{M}=\mathrm{Ge}, \mathrm{Ga}$ and $\mathrm{Zn})$ films. 
directly proportional to the $E_{\mathrm{g}}$ value, which is denoted as the intercept of $\sqrt{\alpha h v} v s$. $h v$ at $\sqrt{\alpha h v}=0$ (table 4). The $E_{\mathrm{g}}$ value decreases with the addition of $\mathrm{Ga}, \mathrm{Ge}$ and $\mathrm{Zn}$ contents because of the Se-Se bonds with high optical gap $\left(E_{\mathrm{g}}=1.85\right.$ $\mathrm{eV}$ ), were replaced by $\mathrm{Ge}-\mathrm{Se}, \mathrm{Ga}-\mathrm{Se}$ and $\mathrm{Zn}-\mathrm{Se}$ bonds.

On the other hand, where the $\alpha$-values are less than $10^{4}$ the energy dependence of the absorption coefficient can be expressed as [35]:

$$
\alpha=\alpha_{0} e^{h v / \gamma}
$$

where $\alpha_{0}$ is a constant and $\gamma$ is related to the width of the band tail of the localized state at the conduction or valence band edge [36]. When the $\alpha$-values in the logarithmic form were plotted against $h v$ as investigated in figure $5 \mathrm{~b}$, the reciprocal of the slope gives the $\gamma$-value. The deduced $\gamma$-values are listed in table 4 . In this table it was observed that the decrease in $E_{\mathrm{g}}$ values (figure 5a) of amorphous films can be explained by the increase of the tailing of the band into the gap, i.e., increase of $\gamma$-values with the replacement of Se by $\mathrm{Ge}, \mathrm{Ga}$ and $\mathrm{Zn}$ contents [37]. This increase in the width of the band tail can be explained by increasing the disorder of the system leading to a decrease in the bandgap $\left(E_{\mathrm{g}}\right)$ values when Se atoms was replaced by Ge, Ge or $\mathrm{Zn}$. Moreover, according to the preceding discussion it was evident that, Tauc's model that is based on the electronic transitions between the localized states in the band edge tails may well be valid for such films.

Wemple and DiDomenico (WDD) suggested that, the energy dependence of the refractive index of material obeys the following dispersion relationship [38]:

$$
\left(n^{2}(h v)-1\right)^{-1}=\frac{E_{0}^{2}-h v^{2}}{E_{\mathrm{d}} E_{0}},
$$

where $E_{0}$ is the oscillator energy and $E_{\mathrm{d}}$ the oscillator strength. $E_{0}$ and $E_{\mathrm{d}}$ were determined from the intercept of $E_{0} / E_{\mathrm{d}}$ and slope $\left(E_{0} E_{\mathrm{d}}\right)^{-1}$, respectively, of the straight fits in figure 6. $E_{0}$ is the average energy gap and it decreases with the addition of $\mathrm{Ge}, \mathrm{Ga}$ or $\mathrm{Zn}$ by only 5 at.\% at the expense of Se atoms. This behaviour of $E_{0}$ as well as that observed for the optical bandgap was confirmed by the observed red shift in the transmittance spectra. Also, the $E_{0}$ value scales with the Tauc's gap, i.e., $E_{\mathrm{g}} \sim 0.5 E_{0}$ [39]. The static refractive index $\left(n_{0}\right)$, i.e., the refractive index when $h v \rightarrow 0$, was also investigated using the above equation. The $n_{0}$ values increase because of the formation of more polarizable $\mathrm{Ge}-\mathrm{Se}, \mathrm{Ga}-\mathrm{Se}$ and $\mathrm{Zn}-\mathrm{Se}$ bonds in the MSe films. Also, the oscillator strength is directly proportional to the coordination number [39]. Therefore, the increase of $E_{\mathrm{d}}$ values is explained by increasing $r$-values with the addition of $\mathrm{Ge}, \mathrm{Ge}$ and $\mathrm{Zn}$ atoms.

The wavelength dependence of the real part of the complex dielectric constants $\left(\varepsilon_{1}\right)$ is written as [39]:

$$
\varepsilon_{1}=n^{2}-K^{2}=\varepsilon_{\infty}-\frac{e^{2}}{\pi c^{2}} \frac{N}{m^{*}} \lambda^{2},
$$

where $\varepsilon_{\infty}$ is the high dielectric constant, $e$ the electronic charge, $c$ the velocity of light, $N / m^{*}$ the ratio of free carrier concentration $(N)$ to the free carrier effective mass $\left(m^{*}\right)$. This equation was employed to determine the parameters $\varepsilon_{\infty}$ and $N / m^{*}$ from the slope and intercept of the fitted straight lines of $\varepsilon_{1} v s . \lambda^{2}$ represented in figure 7 . The deduced values of the $N / m^{*}$ and $\varepsilon_{\infty}$ are listed in table 4 . Both $\varepsilon_{1}$ and $N / m^{*}$ values are increased by replacing 5 at.\% of Se by Ge, Ga or Zn (table 1). $N / m^{*}$ directly correlated to the defect states; thus, an increase in $N / m^{*}$ signifies an increase in defect states that explains the observed decrease in $E_{\mathrm{g}}$ values.

The non-linear optical properties of the films under study can be discussed according to the terms of Tichy and Ticha model [40]. According to these models, the third-order nonlinear susceptibility $\chi^{(3)}$ in esu units is given by Miller's generalized rule, $\chi^{(3)}=A\left(\chi^{(1)}\right)^{4}$, where $A=1.70 \times 10^{-10}$ and

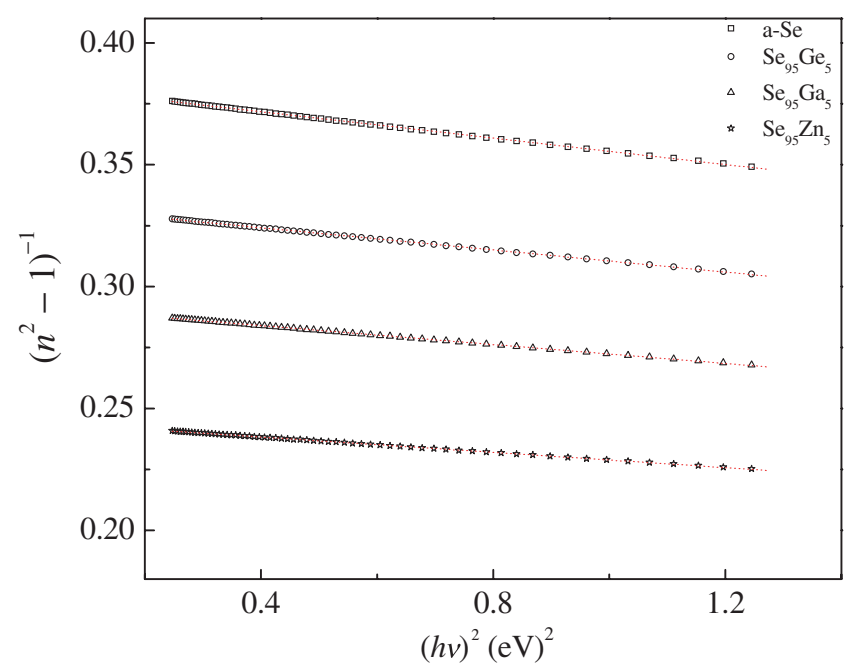

Figure 6. The plots of the refractive index parameter $\left(n^{2}-1\right)^{-1}$ as a function of squared incident photon energy for a-Se and a- $\mathrm{M}_{5} \mathrm{Se}_{95}$

\begin{tabular}{|c|c|c|c|c|c|c|c|c|c|}
\hline Comp. & $\begin{array}{c}B^{0.5} \\
(\mathrm{~cm} \mathrm{eV})^{-1 / 2}\end{array}$ & $\gamma, \mathrm{meV}$ & $E_{\mathrm{g}}$ & $\frac{E_{\mathrm{d}}}{\mathrm{eV}}$ & $E_{0}$ & $E_{0} / E_{\mathrm{g}}$ & $n(0)$ & $\begin{array}{c}N / m^{*}, \\
10^{39} \mathrm{~cm}^{-3}\end{array}$ & $\varepsilon_{\infty}$ \\
\hline $\mathrm{a}-\mathrm{Se}$ & 729.0 & 30.47 & 1.96 & 9.9 & 3.98 & 1.95 & 1.904 & 4.17 & 3.8 \\
\hline $\mathrm{Se}_{95} \mathrm{Ge}_{5}$ & 713.5 & 34.1 & 1.88 & 11.39 & 3.80 & 2.02 & 1.995 & 4.62 & 4.2 \\
\hline $\mathrm{Se}_{95} \mathrm{Ga}_{5}$ & 692.5 & 37.2 & 1.79 & 12.77 & 3.73 & 2.1 & 2.103 & 5.12 & 4.64 \\
\hline $\mathrm{Se}_{95} \mathrm{Zn}_{5}$ & 660.5 & 41 & 1.72 & 14.59 & 3.61 & 2.17 & 2.247 & 3.87 & 5.33 \\
\hline
\end{tabular}
$(\mathrm{M}=\mathrm{Ge}, \mathrm{Ga}$ and $\mathrm{Zn}$ ) films.

Table 4. Some physical properties of a-Se and $\mathrm{Se}_{95} \mathrm{M}_{5}(\mathrm{M}=\mathrm{Ge}, \mathrm{Ga}$ and $\mathrm{Zn})$ films. 
$\chi^{(1)}$ is the linear optical susceptibility that is based on the index of refraction for chalcogenides as [41-43]:

$$
\chi^{(1)}=\left(n^{2}-1\right) / 4 \pi,
$$

Substituting $\chi^{(1)}$ into $\chi^{(3)}$ gives

$$
\chi^{(3)}=\frac{A\left(n^{2}-1\right)^{4}}{(4 \pi)^{4}},
$$

values of $\chi^{(3)}$ have been found to increase when $\mathrm{Ge}, \mathrm{Ga}$ or $\mathrm{Zn}$ replaces Se as seen in figures 8 and 9, respectively, thus, the non-linear index of refraction can be determined through the following equation [41-43]:

$$
n_{2}=\frac{12 \pi \chi^{(3)}}{n} \text {. }
$$

The $n_{2}$ values have been plotted $v s$. $\lambda$ for different films of Se and MSe, as shown in figure 10. The $n_{2}$ values increase

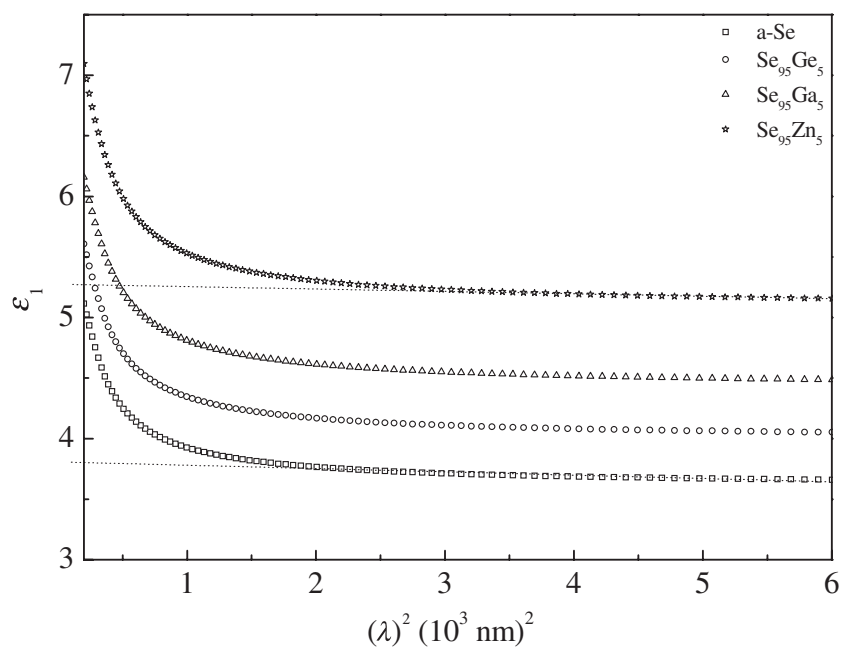

Figure 7. The $\varepsilon_{1} v s . \lambda^{2}$ of a-Se and $\mathrm{M}_{5} \mathrm{Se}_{95}(\mathrm{M}=\mathrm{Ge}, \mathrm{Ga}$ and $\mathrm{Zn})$ films.

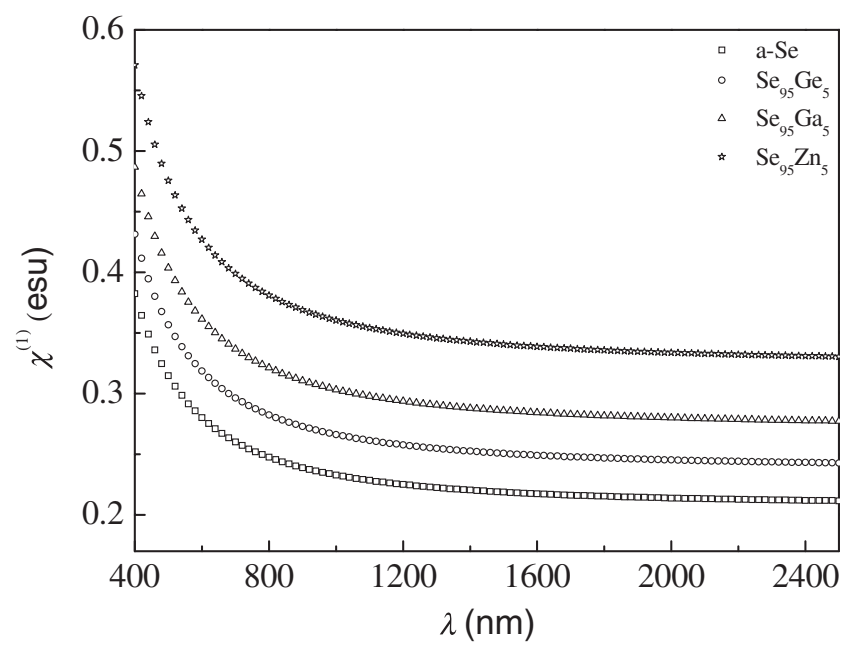

Figure 8. The first order of the electric susceptibility as a function of wavelength for a-Se and $\mathrm{M}_{5} \mathrm{Se}_{95}(\mathrm{M}=\mathrm{Ge}, \mathrm{Ga}$ and $\mathrm{Zn})$ films. when $\mathrm{Ge}, \mathrm{Ga}$ and $\mathrm{Zn}$ replace Se atoms by the amount of 5 at.\%. This behaviour of $n_{2}$ can be correlated to the optical bandgap through this relation $n_{2} \propto\left(E_{\mathrm{g}}\right)^{-4}$ [44]. According to which, $n_{2}$ values are inversely proportional to the fourth order of the $E_{\mathrm{g}}$ values. This showed that the results are consistent with the given relation. Similar behaviour for $n_{2}$ has been observed for other materials such as pure silica $\left(n_{2}=8.1 \times 10^{-14} \mathrm{esu}\right)$ and $\mathrm{As}_{2} \mathrm{~S}_{3}\left(n_{2}=3.51 \times 10^{-11}\right.$ esu) at $800 \mathrm{~nm}[41,42]$. These results clearly indicate that the calculated values of $n_{2}$ for a-Se and MSe films are large in comparison with reported values [41-43]. Glasses with high $n_{2}$ values need moderate laser pulses to change their refractive index. Therefore, the present glassy films may be explored for application in fast optical switching devices. Moreover, the high- $n_{2}$ materials exploiting third-order electronic polarization may have short response time and compact fibre design, which may further boost their application in high-speed signal communication.

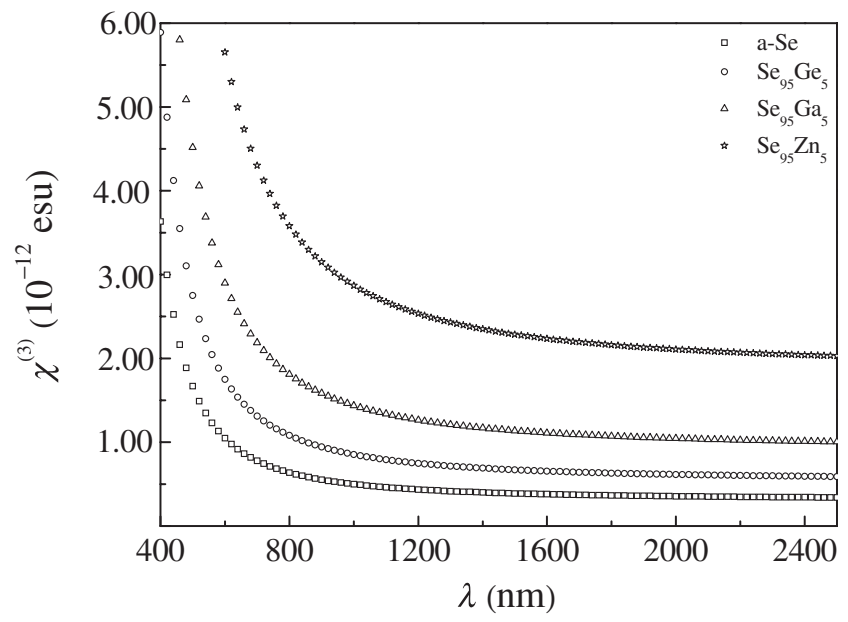

Figure 9. The third order of the electric susceptibility as a function of wavelength for a-Se and $\mathrm{M}_{5} \mathrm{Se}_{95}(\mathrm{M}=\mathrm{Ge}$, Ga and $\mathrm{Zn})$ films.

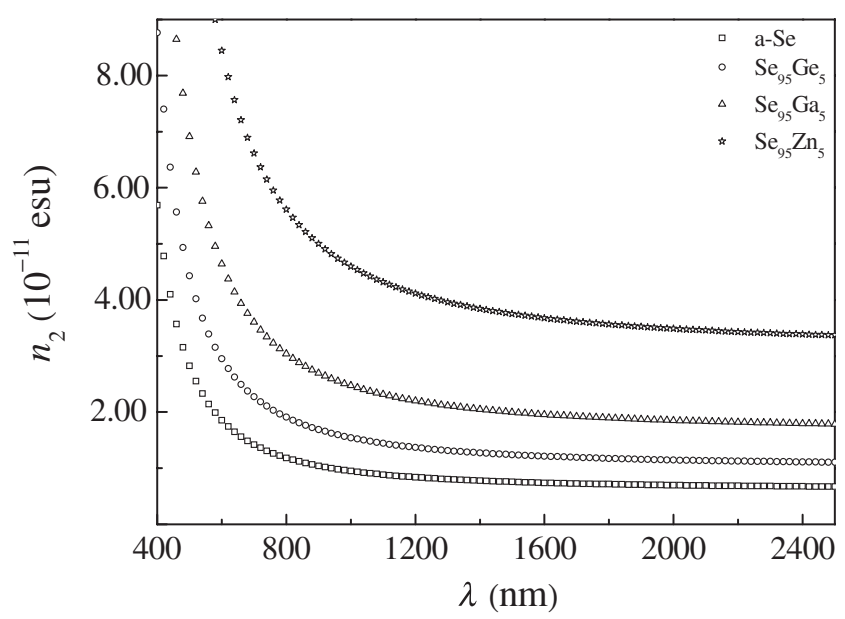

Figure 10. The non-linear index of refraction $n_{2} v s$. $\lambda$ for a-Se and $\mathrm{M}_{5} \mathrm{Se}_{95}(\mathrm{M}=\mathrm{Ge}, \mathrm{Ga}$ and $\mathrm{Zn})$ films. 


\section{Conclusions}

A red shift in the transmission spectrum gradually increases on replacing $\mathrm{Se}(5$ at.\%) with $\mathrm{Ge}, \mathrm{Ga}$ and $\mathrm{Zn}$. This process was attributed to the decrease of the force constant $\left(K_{\mathrm{r}}\right)$ as the $\mathrm{Ge}, \mathrm{Ga}$ and $\mathrm{Zn}$ atoms were replaced with $\mathrm{Se}$ atoms. As a result, the optical bandgap $\left(E_{\mathrm{g}}\right)$ and the absorption edge constant $(\sqrt{B})$ are decreased, because of the increase in the width of localized states in the present films. The allowed indirect transition successfully describes the absorption mechanism in these films. The linear refractive index increases that was ascribed to the formation of more polarizable Ge-Se, Ga-S and $\mathrm{Zn}-\mathrm{Se}$ bonds was confirmed by IR results. The refractive index in the transparent range was well discussed according to WDD model. The oscillator strength $\left(E_{\mathrm{d}}\right)$ and the high frequency dielectric constant $\left(\varepsilon_{\infty}\right)$ increased, but the oscillator energy $\left(E_{0}\right)$ decreases with the addition of $\mathrm{Ge}, \mathrm{Ge}$ and $\mathrm{Zn}$. The $E_{0}$ scales the optical bandgap $\left(E_{0} \sim 2 E_{\mathrm{g}}\right)$. An increase in localized states has also been confirmed by an increase in $N / m^{*}$ values. The static refractive index $n(0)$ increases from 1.904 to 2.247 for a-Se and $\mathrm{M}_{5} \mathrm{Se}_{95}(\mathrm{M}=\mathrm{Ge}, \mathrm{Ga}$ and $\mathrm{Zn})$ films. The first and third order of electric susceptibility $\left(\chi^{(1)}\right.$ and $\left.\chi^{(2)}\right)$ and non-linear index of refraction $\left(n_{2}\right)$ were investigated for a-Se and $\mathrm{M}_{5} \mathrm{Se}_{95}$. The non-linear refractive indices $\left(n_{2}\right)$ increase with the addition of $\mathrm{Ge}, \mathrm{Ga}$ and $\mathrm{Zn}$ and are found to be in the order of $10^{-10}$ esu. Also, the $n_{2}$ values for a-Se and $\mathrm{M}_{5} \mathrm{Se}_{95}$ are larger than those previously published. The material with higher nonlinear optical properties such as $\mathrm{Zn}_{5} \mathrm{Se}_{95}$ may be used in the application of high-speed signal communications.

\section{References}

[1] Pelusi M D, Ta'eed V G, Fu L, Mägi E, Lamont M R E, Madden S, Choi D Y, Bulla D A P, Luther-Davies B and Eggleton B J 2008 IEEE J. Sel. Top. Quantum Electron. 14529

[2] Chen N K, Kuan P W, Zhang J, Zhang L, Hu L, Lin C and Tong L 2010 Opt. Express 1825615

[3] Tai C Y, Wilkinson J S, Perney N M B, Netti M C, Cattaneo F, Finlayson C E and Baumberg J J 2004 Opt. Express 125110

[4] Ta'eed V G, Baker N J, Fu L, Finsterbusch K, Lamont M R E, Moss D J, Nguyen H C, Eggleton B J, Choi D Y, Madden S and Luther-Davies B 2007 Opt. Express 159205

[5] Cui S, Chahal R, Boussard-Plédel C, Nazabal V, Doualan J L, Troles J, Lucas J and Bureau B 2013 Molecules 185373

[6] Gupta P and Bhatnagar P K 2000 Mater. Char. 45167

[7] Sysoev B I, Bezryadin N N and Shlyk Y K 1986 Phys. Status Solidi A Appl. Res. 95 k169

[8] Adachi S and Shindo Y 1992 J. Appl. Phys. 71428

[9] Brudnyia V N, Kosobutsky A V and Sarkisova S Y 2010 Semiconductors 441158

[10] Petkov P 2002 J. Optoelectron. Adv. Mater. 4747

[11] Balboul M R, Hosni H M and Fayek S A 2012 Radiat. Phys. Chem. 811848
[12] Dutsyak I S, Pavlyshyn A Z, Margolych I I and Romanyuk R R 1996 Radiat. Eff. Defect Solids 139253

[13] Ojima T and Adachi S 1997 J. Appl. Phys. 823105

[14] Petkov K, Todorov R, Vassilev V and Aljihmani L 2013 Photo- and thermo-induced changes in optical constants and structure of thin films from GeSe2-GeTe-ZnTe system, in: Physics Procedia, p 142

[15] Reyes J, Márquez E, Ramírez-Malo J B, Corrales C, Fernández-Peña J, Villares P and Jiménez-Garay R $1995 \mathrm{~J}$. Mater. Sci. 304133

[16] Nirmal M, Dabbousi B O, Bawendi M G, Macklin J J, Trautman J K, Harris T D and Brus L E 1996 Nature 383802

[17] Quinlan F T, Kuther J, Tremel W, Knoll W, Risbud S and Stroeve P 2000 Langmuir 164049

[18] Abdel-Rahim M A, Hafiz M M and Alwany A E B 2012 Opt. Laser Technol. 441116

[19] Doweidar H and Saddeek Y B 2009 J. Non-Cryst. Solids 355 348

[20] Othman A A, Aly K A and Abousehly A M 2007 Thin Solid Films $\mathbf{5 1 5} 3507$

[21] Aly K A and Abdel-Rahim F M 2013 J. Alloys Compd. 561 284

[22] Aly K A, Abd Elnaeim A M, Afify N and Abousehly A M 2012 J. Non-Cryst. Solids 3582759

[23] Abdel-Rahim F M, Aly K A and Dahshan A 2011 Mater. Chem. Phys. 128543

[24] Tichý L and Tichá H 1995 J. Non-Cryst. Solids 189141

[25] Bicerano J and Ovshinsky S R 1985 J. Non-Cryst. Solids 7475

[26] Dahshan A and Aly K A 2015 J. Non-Cryst. Solids 40862

[27] Singh A K 2012 Rev. Adv. Sci. Eng. 1292

[28] https://www.webelements.com/

[29] Goyal D R and Maan A S 1995 J. Non-Cryst. Solids 183182

[30] Gordy W 1946 J. Chem. Phys. 14 305-320

[31] Pauling L 1962 The nature of the chemical bonds (Ithaca, United States: Cornell University Press)

[32] Somayajulu G R 1958 J. Chem. Phys. 28814

[33] Doweidar H and Saddeek Y B 2010 J. Non-Cryst. Solids 356 1452

[34] Swanepoel R 1983 J. Phys. E Sci. Inst. 161214

[35] Tauc J 1967 Science 1581543

[36] Aly K A, Dahshan A and Abousehly A M 2008 Philos. Mag. 8847

[37] Mott N F, Davis E A and Street R A 1975 Philos. Mag. 32961

[38] Wemple S H and DiDomenico M 1971 Phys. Rev. B 31338

[39] Sharma P, Dahshan A and Aly K A 2014 J. Alloys Compd. 616323

[40] Tichá H and Tichý L 2002 J. Optoelectron. Adv. Mater. 4381

[41] Smolorz S, Wise F and Borrelli N F 1999 Opt. Lett. 241103

[42] Asobe M, Kanamori T and Kubodera K I 1993 IEEE J. Quant. Electron. 292325

[43] Sharda S, Sharma N, Sharma P and Sharma V 2013 J. Electron. Mater. 423367

[44] Moss T S 1985 Phys. Status Solidi B Basic Res. 131415 